\section{Heroin dependence in an English town:}

\section{3-year follow-up}

\author{
NEHKANT H. (RAJ) RATHOD, W. MARY ADDENBROOKE \\ and ALAN F. ROSENBACH
}

\begin{abstract}
Background There has been nolongterm study of people addicted to injected heroin who have been treated without the prescribing of substitute opioids.
\end{abstract}

\begin{abstract}
Aims To investigate the outcome for patients treated for injected heroin addiction 33 years after they were first seen, and 26 years after they were first followed up, in terms of sustained abstinence, continuing maintenance on methadone and deaths.
\end{abstract}

Method Eighty-six people with heroin addiction first seen in 1966-1967 in a small town in the south-east of England were located and their clinical state assessed using multiple sources, including personal interviews with a proportion of the cohort.

Results Forty-two per cent of the cohort had been abstinent for at least 10 years; $10 \%$ were taking methadone and were classified as addicted; and 22\% had died. Eight per cent of the cohort could not be located.

\section{Conclusions Results proved}

favourable in the above three parameters compared with other long-term studies.

Declaration of interest None.
We report here on a cohort of people with heroin addiction comprising the first 86 patients who attended for therapeutic intervention between 1966 and 1967 and were diagnosed as dependent on heroin by injection. The study explores changes in the drug-using pattern and lifestyle of each individual, as well as examining mortality and causes of death. The cohort emerged from a community-based epidemiological study in a town in the south-east of England, which had a population of approximately 54000 in 1966, and provided good housing and employment (de Alarcon \& Rathod, 1968). In the 1960s the labour demands could not be met from the labour force. Unemployment in 1991 was 5\% (Office for National Statistics, 1991). A previous follow-up of the cohort was reported in 1977 (Rathod, 1977). At the time of first encounter, the patients were aged 16-20 years, were single and living with their parents. They all injected heroin. The cohort currently consists of 75 men and 11 women, as in the previous studies (de Alarcon \& Rathod, 1968; Rathod, 1972, 1977). An account of the spread of injecting is described elsewhere (de Alarcon, 1969). All the patients were treated in the local general psychiatric service, which differed from most other UK services for people with heroin addiction in that it did not prescribe substitute opioids for 23 years after recruitment of the cohort (that is, until 1989), and to the best of our knowledge the same practice was followed by all general practitioners in the locality. The main provisions of the service were immediate help on an out-patient, day-patient or in-patient basis in times of crisis; personal counselling; regular follow-up; an ongoing relapse prevention group; and symptomatic relief with drugs other than opioids.

\section{METHOD}

\section{Channels for tracing the cohort and recording information}

Collection of data took place between 1966 and 1999. The local ethics committee approved the study. As in previous studies, we continued to rely on collecting information from a variety of sources and performed cross-checks for reliability.

\section{Local sources}

The following local sources were used:

(a) Our own records, including patient 'diaries'. The latter were not personal diaries, but records of factual information maintained by members of the staff (Rathod, 1977). They involved the ongoing recording of up-to-date information on patients from multiple sources, including the local press and patients still in contact with the service.

(b) Local general practitioners. Many of the individuals in the cohort were registered with the same doctor as they had been at the time of the first follow-up study. When this was not the case, we consulted the local Medical Adviser in Primary Care, who identified the general practitioner of each patient still registered in the locality.

(c) The local coroner.

\section{National sources}

National sources included the Home Office and the Office for National Statistics.

(a) The Home Office Index of Addicts retained records of new or re-notified cases of addiction until it closed in 1997. However, when a person ceased to be treated for addiction, the Home Office was not necessarily informed (and usually was not). This source provided us with information on prison medical officers and drug dependency clinics which had had contact with our cohort members.

(b) The Office for National Statistics held records of deaths and supplied copies of the relevant death certificates to us. It also informed us of the health authorities of cohort members who were registered with a general practitioner elsewhere or who had left the country. We were able to make contact with the health authorities and a few general practitioners and patients through this source. 


\section{Data collection}

A questionnaire was used as a guideline when interviewing general practitioners and making a record search; this was done in 28 cases $(32 \%)$. Another questionnaire was used as a guide to elicit information in personal interviews with former patients, who we invited to come to the hospital. The interviews, which lasted $90 \mathrm{~min}$ or more, were recorded, with the patient's consent; 17 patients $(20 \%)$ were interviewed. Copies of death certificates were obtained from the Office for National Statistics (17 cases) and the local coroner's office ( 2 cases) for the 19 cohort members (22\%) who had died.

\section{Assessment of drug status}

Drug status was ascertained by clinical judgement, founded upon information from a range of sources as described above, for example medical records and other official sources. The criterion of drug status adopted was that the person had been abstinent or receiving methadone maintenance therapy for at least 10 years prior to the collection of data. This cutoff point was chosen because three of the group currently taking methadone had been abstinent from opiates for up to 5 years and had then relapsed. Therefore, to be on the safe side, we opted for a period of 10 years where we believed that relapse was much less likely, as the results have proved.

\section{RESULTS}

\section{Information gathering}

The summary of information in Table 1 shows that we had varying degrees of information on 79 individuals (92\%). The results are based on 64 persons $(74 \%)$ for whom we had reliable information; these included 45 persons (52\%) who were alive and 19 persons $(22 \%)$ who were dead. Information on 15 persons $(18 \%)$ was assessed to be insufficient to merit inclusion in the results. In the case of $10(12 \%)$ of these, the Office for National Statistics was able to provide information about the health authority with which the individual was registered, but we were unsuccessful in eliciting any further clinical information. We had some clinical information on the other $5(6 \%)$, but it could not be corroborated from official sources. We classified these 15 cases under 'insufficient information'. We had no information on 7 individuals because 2 had emigrated and 5
Table I Tracing the cohort members and gathering data $(n=86)$

\begin{tabular}{lc}
\hline & $n(\%)$ \\
\hline $\begin{array}{l}\text { Corroborated information } \\
\text { Interviewed }\end{array}$ & $17(20)$ \\
Clinical information from a & $28(32)$ \\
corroborated source & \\
Died: copy of death certificate & $19(22)$ \\
obtained & \\
Total & $64(74)$ \\
Uncorroborated information & \\
Area of residence only known & $10(12)$ \\
Hearsay information & $5(6)$ \\
Total & $15(18)$ \\
No information & \\
Emigrated & $2(2)$ \\
Not located & $5(6)$ \\
Total & $7(8)$ \\
\hline
\end{tabular}

could not be located. However, we can be assured that apart from these 7 cases, the Office for National Statistics would have had records of any deaths in the remainder of the cohort and we can therefore assume that they were alive.

\section{Drug status}

Thirty-six people in the cohort $(80 \%$ of those alive, $42 \%$ of the total cohort) were not using opioids, and $9(20 \%$ of those alive, $10 \%$ of the cohort) were receiving methadone maintenance therapy. As mentioned above, this status had been maintained for at least 10 years. There was no significant difference in the proportion of those not using opioids and those using methadone among those married or cohabiting (56v. 66\%), and there was no noticeable difference between the two groups as far as employment was concerned (Table 2). This could be due to the fact that unemployment has always been low in this town.

\section{Use of other drugs}

Seven of the abstinent group had at some time experienced problems from excessive use of alcohol. Six of them also had been registered with clinics or private practitioners outside our area and had received heroin or methadone for a few years in the early 1970s. At least four of the people using methadone had serious problems with alcohol and all of them used other drugs.

\section{Deaths}

Nineteen people (22\%) had died, 2 during the period of information gathering (Table 3). One had been interviewed (but has not been included in the category of the interviewed listed above), and clinical information was obtained from the general practitioner on the other. This amounts to 220 deaths per 1000 , compared with the crude national death rate of 11.8 per 1000 for the year 1966 and 10.6 per 1000 for the year 1997 (Office for National Statistics, 1997). Of the 19 dead, 17 were men and 2 were women. Twelve deaths occurred in people under the age of 40 years. The mean age at time of death was 33 years, the youngest being 18 years, the oldest 49 years. Information on marital status was meagre. Seventeen of the death certificates stated an occupation, but in only two cases was there

Table 2 Summary of reliable data on those alive (age range 46-52 years) $n$

$\begin{array}{lr}\text { Civil status } & \\ \text { Single } & 5 \\ \text { Married/cohabiting } & 27 \\ \text { Widowed } & \mathrm{I} \\ \text { Divorced/separated } & 6 \\ \text { Not known } & 6 \\ \text { Employment status } & 21 \\ \text { Employed } & \mathrm{II} \\ \text { Unemployed } & 5 \\ \text { Disabled } & 8 \\ \text { Not known } & \end{array}$




\begin{tabular}{|c|c|}
\hline Age at death & Causes of death as notified on death certificate \\
\hline \multicolumn{2}{|l|}{$20-29$ years } \\
\hline Case 8 & Asphyxia due to narcotic poisoning; addiction to drugs \\
\hline Case 10 & Haemorrhage due to ruptured liver, car hit car; open verdict re drugs \\
\hline Case 19 & $\begin{array}{l}\text { Respiratory failure; methadone intoxication and repeated intravenous injection } \\
\text { of contents of Seconal [secobarbital] capsules; addiction to drugs }\end{array}$ \\
\hline Case 45 & Cardiac arrest; bronchopneumonia; drug addiction; misadventure \\
\hline Case 75 & $\begin{array}{l}\text { Multiple injuries; fell from moving train while under the influence of drink; } \\
\text { misadventure }\end{array}$ \\
\hline \multicolumn{2}{|l|}{$30-39$ years } \\
\hline Case I & Myocardial ischaemia; coronary atheroma \\
\hline Case 30 & Overdose of methadone; misadventure (registered drug addict) \\
\hline Case 33 & Overdose of methadone; misadventure \\
\hline Case 38 & Addiction to drugs (multiple drugs) \\
\hline Case 58 & Morphine poisoning; misadventure \\
\hline Case 62 & $\begin{array}{l}\text { Multiple injuries; found dead outside his abode after a fall; took his own life } \\
\text { on account of his illness }\end{array}$ \\
\hline Case 83 & Chloral hydrate poisoning; open verdict \\
\hline \multicolumn{2}{|l|}{ 40-49 years } \\
\hline Case 3 & Liver failure; liver cancer; hepatitis C \\
\hline Case 15 & $\begin{array}{l}\text { Left pneumothorax and collapse of left lung due to chronic obstructive airways } \\
\text { disease due to smoking }\end{array}$ \\
\hline Case 24 & Aspiration pneumonia; chronic alcoholism; boxer's brain; severe fatty change to liver \\
\hline Case 34 & $\begin{array}{l}\text { Klebsiella bronchopneumonia; chronic renal failure secondary to } \\
\text { cryoglobulinaemia; acute pancreatitis }\end{array}$ \\
\hline Case 44 & Methadone poisoning; non-dependent abuse of a drug \\
\hline Case 57 & Chest infection; liver failure due to sclerosis \\
\hline Case 6I & Renal failure; hepatitis C-induced chronic liver disease \\
\hline
\end{tabular}

information on current employment. One person had been an invalid for many years.

In 11 individuals (58\% of deaths) overdose of drugs (excluding alcohol) was implicated, primarily in the under-40 age group. Only one such death occurred in the age group 40-49 years. Overdose of opioids was the cause in eight cases, in all of which the individual was receiving methadone from a clinic outside our area. One death (case 44) was attributed to methadone poisoning in a non-dependent person. We were informed by the general practitioner that the person in case 3 was receiving methadone maintenance, even though the death certificate gave 'liver failure and cancer of the liver' as the cause of death. In case 1 , the diary entry near the time of death mentioned excessive use of methylphenidate, although the death certificate gave the cause of death as 'myocardial ischaemia'. Of the remaining cases, two involved chronic misuse of alcohol, but the actual cause of death was multiple injuries during a fall in one case and aspiration pneumonia/liver failure in the other. Two other people died of multiple injuries in successful suicide attempts, and the remaining four died of natural causes. In none of these 8 cases was there any reason to suspect use of opioids. In the 40-49 year age category, 4 out of 7 had some liver pathology. Unfortunately, we have no further details to suggest the cause of this.

\section{DISCUSSION}

This report is the latest in a series on the cohort (de Alarcon \& Rathod, 1968; de Alarcon, 1969; Rathod, 1972, 1977). One limitation is that biochemical tests were not used to verify current drug status, primarily because asking for such tests could have jeopardised trust and such procedures were not practically possible.

The study differs in three significant respects from most others. First, the sample is derived from a small town, and the patients were treated in a general psychiatric service, whereas all other longitudinal studies are based on city populations and their cohorts were treated in drug dependency clinics in the UK or special treatment facilities in the USA. Second, the mode of spread of injecting practices was through established social networks and this might have affected the outcome, in the sense that individuals are influenced by the behaviour of their friends. However, we have no proof of this and to our knowledge there is no other study on the relationship between mode of spread and outcome. Third, substitute opioids were not prescribed by our service for 23 years after recruitment of the cohort began, and as there was no other facility in the area patients were left with few options. They either had to accept treatment locally, forgo treatment or seek help elsewhere, an option that entailed a risk of exposing their 'addiction' to family and friends and also of admitting a loss of control over their drug-using behaviour - a major shift in attitude. This factor might have acted as an incentive towards abstinence in the early years of the service, but is no longer relevant because methadone prescribing started in 1989 and continues in the local service.

\section{Attrition of the cohort and non-availability of data}

We were unable to contact seven of the cohort members. This attrition rate of $8 \%$ compares favourably with many other reports, for example $14 \%$ at 10-year follow-up (Edwards \& Goldie, 1987) and $17 \%$ at 6-7 year follow-up (Willis \& Osbourne, 1978). This may partly be due to the size of the town and the relative stability of the population compared with metropolitan areas. It could also have been due to the service emphasising the importance of keeping in touch with former patients and the long-standing contact between N.H.R. and the local general practitioners.

How to classify the drug status of the cohort members for whom there is no information poses a dilemma. In our study this applied to 17 individuals: for 10 we could not obtain any clinical information although we knew they were still alive, 5 could not be traced and 2 had emigrated. This inevitably affects the total results.

It is unfortunate that we were unable to interview more of the cohort members. 
Table 4 'One-off' follow-up studies of at least 10 years' duration in the UK

\begin{tabular}{lcccccc}
\hline Study & $\begin{array}{c}\text { Follow-up } \\
\text { (years) }\end{array}$ & $\begin{array}{c}\text { Sample size } \\
n\end{array}$ & $\begin{array}{c}\text { Dead } \\
\%\end{array}$ & $\begin{array}{c}\text { Abstinent } \\
\%\end{array}$ & $\begin{array}{c}\text { Addicted } \\
\%\end{array}$ & $\begin{array}{c}\text { Not known } \\
\%\end{array}$ \\
\hline Gordon (1983) & 10 & 60 & 18 & 62 & 20 & 18 \\
Cottrell et al (1985) & II & 83 & 20 & 16 & 35 & 20 \\
Edwards \& Goldie (1987) & 10 & 74 & 15 & 43 & 8 & 34 \\
\hline
\end{tabular}

I. This terminology of the authors is maintained. All the authors reported on studies of patients using methadone.

This was partly due to the reluctance of two health centres in the town to allow us to contact these patients, in spite of our having the approval of the local ethics committee, and partly due to an understandable reluctance on the part of some of the people we contacted to be interviewed so long after their treatment. However, we can be fairly confident that as far as drug status is concerned, since the general practitioners whom we interviewed had up-to-date, detailed information about both the physical and mental health of the individuals and often also of their families in many cases, they would be unlikely to have missed evidence of long-term use of opioids.

\section{Comparison of outcomes with the first follow-up of this cohort}

The first follow-up period was up to 6 years (Rathod, 1977). At that assessment 13\% $(n=11)$ were judged to have stopped using any illegal drugs, $51 \%(n=44)$ were still injecting, $6 \%(n=5)$ had died and $12 \%$ $(n=10)$ had experienced alcohol-related problems. Precise comparisons between the outcomes of the 1977 study and this study are not possible, the main reason being the large number of cases in this study for which we have no information. However, the main trends are clear: $42 \%$ are not using opioids and only $10 \%$ are still using them, but $22 \%$ have died.

\section{Comparison with other long-term follow-up studies}

Long-term follow-up studies resemble postmortem examinations: any concordance among studies - despite differences in the nature of the cohorts, treatments and the methods of collecting and processing the data - will illustrate the natural history of a disorder. There are two types of study: 'one-off' and repeat studies. Repeat studies follow up the same population some years later and thus the cohort acts as its own control; they reveal trends in outcome over the years which may help future planning of services.

We reviewed the existing three 'one-off' British studies with a follow-up period of 10 years and a minimum cohort-size of 60 (Table 4). The death rates are comparable $(15-20 \%)$ but the rates of abstinence and methadone dependency differ. This may be due to the nature of the cohort, the service or other factors. Authors also differ in their definition of 'non-addicted' patients (Cottrell et al, 1985).

We found few repeat studies; these were of cohorts in England, California and New York (Table 5). The only common feature was the prescribing of substitute opioids (methadone).

\section{Outlook}

It is encouraging that trend studies (Table 5) show agreement on certain aspects of the lives of people with narcotic addiction. The proportion of those maintaining sustained abstinence rises with time, and simultaneously the proportion of those still addicted declines, despite the pessimistic views expressed by some, such as Hser et al (2001) and Goldstein \& Herrera (1995). However, there is no way of knowing whether the proportion of those dying because of the effects of drug-taking reaches a peak after about 20 years. One

Table 5 Repeat studies from the UK and USA

\begin{tabular}{|c|c|c|c|c|c|c|}
\hline Study & $\begin{array}{c}\text { Duration of } \\
\text { follow-up (years) }\end{array}$ & $\begin{array}{c}\text { Attrition rate } \\
\%\end{array}$ & $\begin{array}{c}\text { Deaths } \\
\%\end{array}$ & $\begin{array}{c}\text { Addicted' } \\
\%\end{array}$ & $\begin{array}{c}\text { Abstinent } \\
\%\end{array}$ & Sample size and derivation \\
\hline \multicolumn{7}{|l|}{ UK study: London } \\
\hline Stimson et al (1978) & 7 & 3 & 12 & 48 & $31^{2}$ & I 28 representative patients from 13 drug \\
\hline Wille (I98I) & 10 & 5 & 15 & 38 & $31^{3}$ & dependency clinics in London \\
\hline Oppenheimer et al (1994) & 22 & & 34 & & & \\
\hline \multicolumn{7}{|l|}{ US study: California } \\
\hline McGlothlin et al (1977) & 10 & 5 & 13.8 & $38.7^{4}$ & $37.8^{4}$ & 58I White men admitted to California \\
\hline Hser et al (1993) & 24 & II & 27.7 & $39.8^{5}$ & $41^{5}$ & Drug Addiction Program 1962-1964 \\
\hline Hser et al (200 I) & 33 & & 48.9 & 30.2 & 55.8 & \\
\hline \multicolumn{7}{|l|}{ US study: New York } \\
\hline Vaillant (1966) & 12 & 6 & II & 41 & 23 & 100 people with narcotic addiction \\
\hline Vaillant (1973) & 20 & 10 & 23 & 25 & 35 & admitted to Lexington Hospital, New York \\
\hline \multicolumn{7}{|l|}{ UK study: Crawley } \\
\hline Rathod (1977) & $2-6$ & 5 & 6 & 52 & 13 & 86 people with heroin addiction in \\
\hline This paper & $>30$ & 8 & 22 & 10 & 42 & Crawley New Town 1967-1968 \\
\hline
\end{tabular}

I. This terminology of the authors is maintained. All the authors reported on studies of patients using methadone.

2. Including $2.6 \%$ abstinent for more than 2 years.

3. Abstinent for more than 4 years.

4. Figures based on 439 interviewees.

5. Figures based on 354 interviewees. 
worrying feature is the proportion of premature deaths, mostly due to overdoses.

Except for Stimson \& Oppenheimer (1982), few researchers in the UK have explored patients' perceptions of their addiction or of their treatment. We address this aspect elsewhere (Addenbrooke, 2004). Interview-based studies are more frequent in the USA; for example, a 25 -year longitudinal study interviewed 841 participants in order to examine trends in patterns of spontaneous remission and treatment use - an impressive achievement (Price et al, 2001).

\section{Deaths}

We are not the only authors to highlight the high premature death rate and the fact that overdose of drugs is the most common cause (see Tables 4 and 5). As overdose with opioids is often mentioned as a cause of death, a closer monitoring of opioid use, especially the prescribed ones, is called for. We also noticed the frequency of liver pathology mentioned in the death certificates in our study. This is not surprising in those who inject drugs, yet it is rarely highlighted (Vaillant, 1973; Oppenheimer et al, 1994; Goldstein \& Herrera, 1995; Hser et al, 2001). It is possible that regular screening for liver functions may help early detection and treatment. The same could apply in the case of alcohol misuse, which is not insignificant among drug users. Interestingly, seven people in our abstinent group had experienced excessive use of alcohol at some time.

A recent study advocates caution in the prescription of antidepressants to people with heroin addiction, as these therapeutic agents may be implicated in deaths due to overdoses (Cheeta et al, 2004).

\section{Pharmacotherapy in perspective}

The advantages of long-term substitute prescribing of methadone are obvious in terms of increased social stability and the reduction of crime. However, we were struck by the number of premature deaths in people taking methadone, and also by the negative perceptions of life among those who are currently prescribed this opioid. Our study findings suggest that equally satisfactory results are possible without recourse to long-term prescribing of opioids. This points to the necessity of comparing outcomes between people prescribed substitute drugs for addictions and those who are not.

\section{CLINICAL IMPLICATIONS}

- Our results suggest an alternative path to abstinence without the prescribing of substitute opioids.

- The death rate among people who inject heroin should be reduced by regular health screening and intervention.

Repeat follow-up studies of the same cohort may provide a clearer perspective on the natural history of opioid misuse.

\section{LIMITATIONS}

- The cohort was derived from a small provincial town and findings may not be comparable with those from metropolitan areas.

In $18 \%$ of cases, information was deemed unreliable.

We did not use biochemical screening of body fluids.

NEHKANT H. (RAJ) RATHOD, FRCP, FRCPsych, W. MARY ADDENBROOKE, PhD, Society of Analytical Psychology, London; ALAN F. ROSENBACH, MSc, MBA, Commission for Social Care Inspection, London, UK

Correspondence: Dr N. H. Rathod, Corsletts Farm, Broadbridge Heath, Horsham, West Sussex RHI2 3LD, UK. E-mail: rajrathod@onetel.com

(First received I3 September 2004, final revision 3 December 2004, accepted 28 January 2005)

\section{REFERENCES}

Addenbrooke, M. (2004) An Enquiry into Psychological Aspects of Recovery from Dependence on Psychoactive Substances. PhD Thesis, University of Essex.

Cheeta, S., Schifano, F., Oyefeso, A., et al (2004) Antidepressant-related deaths and antidepressant prescriptions in England and Wales, 1998-2000. British Journal of Psychiatry, 184, 4I-47.

Cottrell, D., Childs-Clarke, A. \& Ghodse, A. H. (1985) British opiate addicts: an II-year follow-up. British journal of Psychiatry, 146, 448-450.

De Alarcon, R. (1969) The spread of heroin abuse in a community. Bulletin on Narcotics, 21, 17-22.

De Alarcon, R. \& Rathod, N. H. (1968) Prevalence and early detection of heroin use. BMJ, I June, 549-553.

Edwards, J. G. \& Goldie, A. (1987) A ten-year followup study of Southampton opiate addicts. British Journal of Psychiatry, 15I, 679-683.

Goldstein, A. \& Herrera, J. (1995) Heroin addiction and methadone treatment in Albuquerque: a 22-year follow-up. Drug and Alcohol Dependence, 40, 139-150.

Gordon, A. M. (1983) Drugs and delinquency: a ten year follow-up of drug clinic patients. British Journal of Psychiatry, 142, 169-173.

Hser, Y.-I., Anglin, D. \& Powers, K. (1993) A 24-year follow-up of California narcotics addicts. Archives of General Psychiatry, 50, 578-584.

Hser, Y.-I., Hoffman, V., Grella, C. E., et al (200I) A

33-year follow-up of narcotics addicts. Archives of General Psychiatry, 58, 503-508.

McGlothlin, W. H., Anglin, M. D. \& Wilson, B. D. (1977) An Evaluation of the California Civil Addicts Program. Rockville, MD: National Institute on Drug Abuse.

Office for National Statistics (1991) Census County Monitors, England and Wales. London: ONS.
Office for National Statistics (1997) Mortality Rates, England and Wales. London: ONS.

Oppenheimer, E., Tobbutt, G., Taylor, C., et al (1994) Death and survival in a cohort of heroin addicts from London clinics: a 22-year follow-up study. Addiction, 89, 1299-1308.

Price, R. K., Risk, N. K. \& Spitznagel, E. L. (200I) Remission from drug abuse over a 25 -year period: patterns of remission and treatment use. American Journal of Public Health, 91, II07-III3.

Rathod, N. H. (1972) The use of heroin and methadone by injection in a new town. British Journal of Addiction, 67, $113-121$.

Rathod, N. H. (1977) Follow-up study of injectors in a provincial town. Drug and Alcohol Dependence, 2, I-2I.

Stimson, G.V. \& Oppenheimer, E. (1982) Heroin Addiction: Treatment and Control in Britain. London: Tavistock.

Stimson, G.V., Oppenheimer, E. \& Thorley, A. (1978) Seven-year follow-up of heroin addicts: drug use and outcome. BMI, i, I190-1192.

Vaillant, G. E. (1966) A I2-year follow-up of New York narcotic addicts I. The natural history of a chronic disease. New England Journal of Medicine, 275, 12821288

Vaillant, G. E. (1973) A 20 -year follow-up of New York narcotic addicts. Archives of General Psychiatry, 29, 237-24l.

Wille, R. (198I) Ten-year follow-up of a representative sample of London heroin addicts: clinic attendance, abstinence and mortality. British Journal of Addiction, 76 $259-266$

Willis, J. H. \& Osbourne, A. B. (1978) What happens to heroin addicts? A follow-up study. British Journal of Addiction, 73, 189-198. 